\title{
Catalytic Enantioselective Arylations: Boron to Zinc Exchange as a Powerful Tool for the Generation of Transferable Aryl Groups
}

\author{
Márcio W. Paixão, ${ }^{*, a}$ Antonio L. Braga ${ }^{*, b}$ and Diogo S. Lüdtke ${ }^{*, c}$ \\ ${ }^{a}$ Instituto de Química, Universidade de São Paulo, 05508-800 São Paulo-SP, Brazil \\ ${ }^{b}$ Departamento de Química, Universidade Federal de Santa Maria, 97105-900 Santa Maria-RS, Brazil \\ ${ }^{c}$ Faculdade de Ciências Farmacêuticas, Universidade de São Paulo, 05508-900 São Paulo-SP, Brazil
}

\begin{abstract}
A transmetalação entre boro e zinco apresenta uma grande importância para diversas aplicações em síntese orgânica, uma vez que permite a formação de novas ligações carbono-carbono entre reagentes organometálicos e espécies eletrofílicas. A arilação direta de aldeídos e, mais raramente de cetonas, de maneira catalítica e enantiosseletiva, empregando catalisadores quirais, têm sido descrita recentemente. Os diaril metanóis opticamente enriquecidos, obtidos nessas reações são precursores valiosos para a síntese de moléculas bioativas. O presente trabalho apresenta uma revisão sobre essa crescente área de atuação e destaca alguns dos desafios que ainda permanecem.
\end{abstract}

The transmetalation between boron and zinc is of great importance for application in organic synthesis, since it allows the formation of new carbon-carbon bonds between organometallic units and electrophiles. The direct arylation of aldehydes or more scarcely ketones, in a catalytic, enantioselective manner using chiral catalysts has been described recently. The enantiomerically enriched diarylmethanols obtained in these reactions are valuable precursors for important bioactive molecules. This review provides a synopsis of this ever-growing field and highlights some of the challenges that still remain.

Keywords: diarylmethanol, boronic acid, boron-to-zinc exchange, asymmetric catalysis

\section{Introduction}

Over the past decades, great progress has been made in the catalytic asymmetric addition of organozinc reagents to aldehydes using chiral amino alcohols as ligands, and products with excellent enantiomeric excess have been achieved with all types of substrates. ${ }^{1}$ More recently, the enantioselective arylation of aldehydes in the presence of a chiral ligand has received special attention since it gives access to chiral diarylmethanols, important precursors for pharmacologically and biologically compounds which include antihistaminic, antiarrhythmic, diuretic, antidepressive, laxative, local-anesthetic and anticholinergic activities (Figure 1). ${ }^{2,3}$ For instance, $(R)$-orphenadrine and $(R)$-neobenodine both display antihistaminic and anticholinergic activity. Other compounds with similar core feature also present important biological activities.

*e-mail: marelloweber@gmail.com; albraga@quimica.ufsm.br; dsludtke@usp.br
Examples are the medically useful histamine $\mathrm{H}_{1}$ antagonists $(S)$-carbinoxamine and $(R, R)$-clemastine and the more selective, second generation $\mathrm{H}_{1}$ antagonist $(S)$-cetirizine di-hydrochloride, which is currently administrated in its enantiomerically pure form for the treatment of allergic diseases. ${ }^{4}$ In addition to their direct applications, chiral diarylmethanols could also serve as intermediates in the synthesis of drugs with a chiral trisubstituted diarylmethane unit, ${ }^{5}$ which is found in many compounds that act as phosphodiesterase-4 (PDE-IV) inhibitors. These compounds have received considerable attention as potential therapeutic agents for the treatment of diseases such as asthma and chronic obstructive pulmonary disease. ${ }^{6}$

Since the pioneering work of $\mathrm{Fu}^{7}{ }^{7}$ several reports concerning the preparation of chiral diarylmethanols by arylzinc addition to aldehydes have been published. ${ }^{8}$ The initial approach was centered in the use of the expensive diphenylzinc as the aryl source (Scheme 1). However, its enantioselective addition to aldehydes is a challenging endeavor, since this reagent is much more reactive than well 


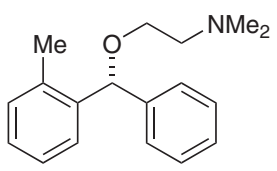

(R)-orphenadrine

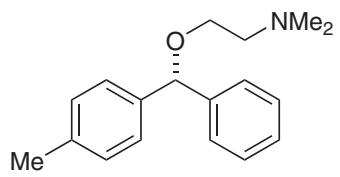

$(R)$-neobenodine

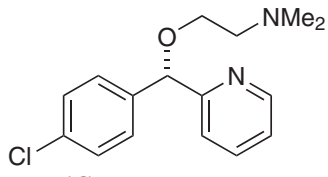

(S)-carbinoxamine
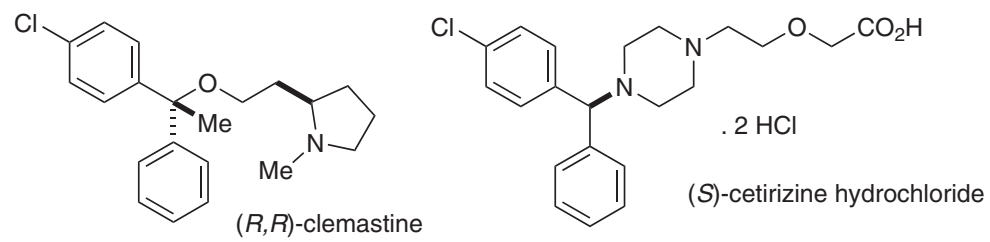

Figure 1. Examples of biologically active compounds derived from diarylmethanols and diarylmethylamines.

known diethylzinc. The uncatalyzed background addition thus competes with the enantioselective pathway, leading to the formation of racemic product.

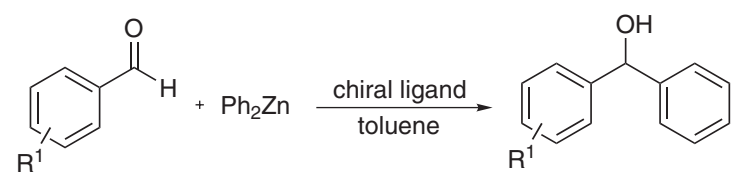

Scheme 1.

In order to circumvent this problem, diethylzinc was found to reduce the reactivity of the arylzinc reagent, by forming phenylethylzinc, which is less reactive than diphenylzinc itself. This strategy improves the overall system performance since the aryl transfer reaction proceeds slowly compared to the reaction with $\mathrm{Ph}_{2} \mathrm{Zn}$ alone. Additionally, it accounts for a higher selectivity for the phenyl transfer and allows the use of reduced amount of the expensive diphenylzinc (Scheme 2), ${ }^{9,10}$

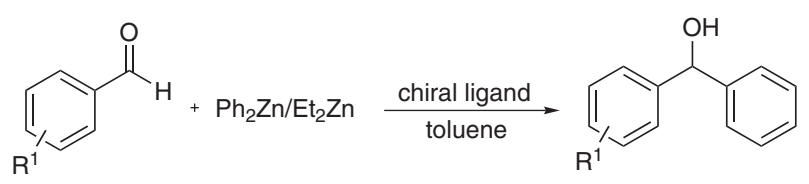

Scheme 2.

These two protocols, however, have a serious drawback. The scope of the aryl group to be transferred is limited to phenyl ring, because only diphenylzinc is a commercially available diarylzinc reagent. Thus, there is a need for the development of methods that would permit the asymmetric transfer of a broader range of substituted aryl groups, starting from cheap and readily accessible sources. In this context, an interesting protocol was recently introduced by Bolm, which take advantage of the use of boronic acids as the source of the nucleophilic aryl species, by a boron-to-zinc ${ }^{11}$ exchange reaction with diethylzinc. ${ }^{12}$ This method now allows the exploitation of a broader range of substituted aryl transfer reagents, since numerous arylboronic acids are sold by commercial suppliers and even more interesting is the feature that this methodology permits that both enantiomers of a given product can be prepared using the same chiral ligand, just by appropriate choice of both reaction partners; aryl boronic acid and aldehyde (Scheme 3).

\section{Mechanistic Considerations}

Although the exact nature of the actual catalyst is still not well understood, it is believed that the boron-to-zinc exchange reaction leads to the formation of PhZnEt, as already investigated by Pericàs ${ }^{10}$ and Bolm $/$ Norrby $^{13}$ for the addition of $\mathrm{Ph}_{2} \mathrm{Zn} / \mathrm{Et}_{2} \mathrm{Zn}$. On the basis of DFT calculations, they independently proposed that when a diphenylzinc and diethylzinc are mixed in solution, a group exchange takes place and the equilibrium is completely shifted towards the mixed species PhZnEt. This mixed zinc reagent in the presence of a chiral ligand (i.e. an amino alcohol) may form preferentially an ethyl-substituted chiral zinc complex, which then reacts with aldehydes through a tricyclic transition state delivering preferentially the product of arylation (Scheme 6).

More recently, a very interesting theoretical and experimental study was published by Maseras, Pericàs and co-workers, dealing with the mechanism of the boron-tozinc exchange reaction, and its application to the catalytic asymmetric arylation of aldehydes..$^{14}$ On the basis of DFT calculations, with a slightly simplified system, consisting in dimethyl(phenyl)boroxine and EtZnMe, they found that a stepwise mechanism involving sequential zinc-to-boron and boron-to-zinc transmetalations seems to be operating in the reaction system (Scheme 4). 


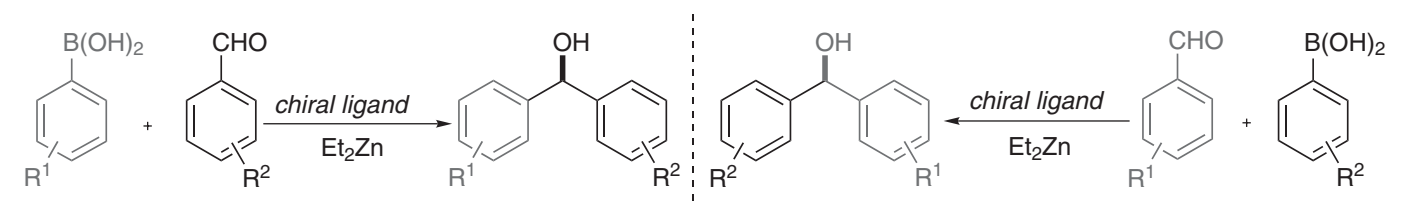

both enantiomers, same chiral ligand

Scheme 3.

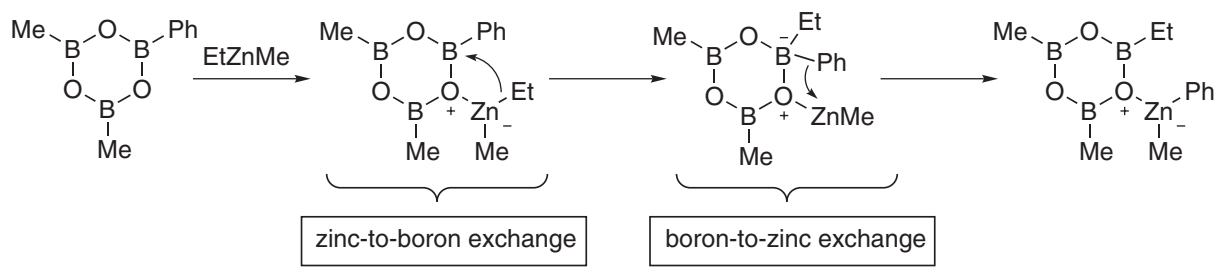

Scheme 4.

The overall process is expected to consist in two easy steps involving migration of a carbon chain from an anionic center to an adjacent site with Lewis acid characteristics. This observation contrasts with the standard experimental procedures encountered in most of the publication of the field, where the transmetalation step typically takes $12 \mathrm{~h}$ at $60{ }^{\circ} \mathrm{C}$. In order to test their hypothesis that the boronto-zinc exchange should occur as a fast step in the whole process, microcalorimetric experiments were carried out, and they revealed that the reactions are expected to reach equilibrium in very short times (15-30 min). Further experimental evidence was obtained by generating $\mathrm{PhZnEt}$ from phenyboronic acid or triphenylboroxine, under the conditions determined by the studies performed. In fact, the transmetalation was found to be completed in $15 \mathrm{~min}$ for $\mathrm{PhB}(\mathrm{OH})_{2}$ and $30 \mathrm{~min}$ for $(\mathrm{PhBO})_{3}$. The $\mathrm{PhZnEt}$ thus generated reacted with $p$-tolualdehyde, in the presence of an chiral amino alcohol, delivering the chiral diarylmethanol in high yields and ee's (Scheme 5).

The active catalyst for asymmetric aryl transfer is, actually, the complex formed by the reaction of the ligand with the PhZnEt formed in the transmetalation step. Thus, as depicted in Scheme 6, the combination of an amino alcohol with the zinc reagent can lead to both structures A (ethyl-substituted) and B (phenyl-substituted). As determined by Bolm/Norrby, ${ }^{13}$ in their theoretical study on the mechanism of the aryl transfer reaction, the species $\mathbf{A}$ is the favored and leads, upon coordination with the aldehyde and another molecule of the organozinc reagent, to the tricyclic transition states anti-trans $\mathbf{C}$ and anti-cis $\mathbf{D}$, which are in line with the dinuclear zinc complexes
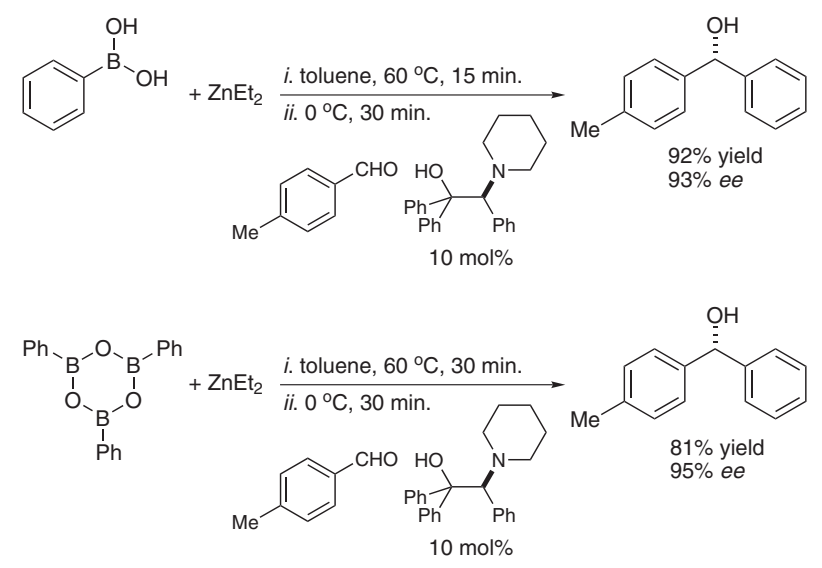

Scheme 5.

proposed by Noyori. ${ }^{15}$ The anti-trans transition state $\mathbf{C}$ should be favored over the anti-cis $\mathbf{D}$, since axial positioning of the aldehyde is avoided, minimizing steric interactions with the ethyl group attached to the zinc atom, in the central four membered ring. The phenyl transfer is favored over the ethyl transfer, since for both, the transition states are reminiscent from the free anion, with the filled lobe pointing between the zinc and the carbonyl $\mathrm{C}$ atom. In the case of the phenyl moiety, additional stabilization is provided by the filled aromatic $\pi$ orbital, which overlaps with the electron-poor $\mathrm{Zn}$ and $\mathrm{C}$ atom orbitals. As a result, the phenyl group easily bends, while the distortion of an ethyl group is a high-energy process, which accounts for the higher selectivity for the phenyl transfer, even in the presence of large excess of the ethyl reagent. 


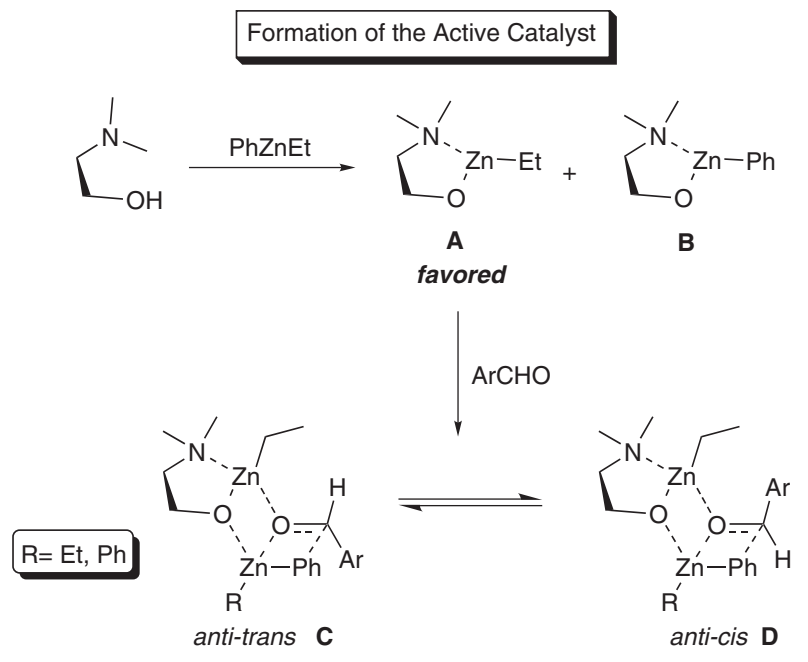

Scheme 6.

\subsection{Asymmetric aryl transfer reaction with chiral amino alcohols and amino alcohol-type ligands}

The first successful ligand developed for this process was the ferrocene-based chiral oxazoline 1 (Scheme 7). ${ }^{9}$ This compound catalyzed the addition of several different aryl boronic acids to a broad range of aromatic aldehydes possessing either electron-donating or electron-withdrawing groups with high levels of enantioselectivity. It is worth mentioning that even aromatic aldehydes bearing an ortho substituent, which have previously proved difficult, afforded the corresponding carbinol in high ee's. The structure of the boronic acid also tolerates some substitution, especially at the para position and the aryl group was transferred with high yields and ee's. Ortho substituted aryl boronic acids were problematic and $e e$ 's were generally lower. The results could be improved even more by the addition of a polyether to the reaction system. ${ }^{16}$ Thus, with the addition of $10 \mathrm{~mol} \%$ of DiMPEG $\left(\mathrm{M}=2000 \mathrm{~g} \cdot \mathrm{mol}^{-1}\right)$ higher $e e^{\text {' }}$ s of the product could be achieved. Significant to point out is that this catalytic system was also suitable for scale up purposes and the same level of enantioselectivity was maintained when the reaction was carried out on a multigram scale. ${ }^{17}$

Bolm and co-workers also succeeded in expanding their methodology to investigate the synthesis of diarylmethanols with two differently substituted aryl groups (Figure 2). ${ }^{18}$ The authors found that most diarylmethanols were performed in good yields and high enantioselectivities. For example, 4-chlorophenyl-2'methylphenylmethanol was obtained in $71 \%$ yield and $91 \%$ $e e$. In the catalysis starting from 4-methylbenzaldehyde and 3-thiophenylboronic acids, diarylmethanol was formed with $95 \%$ ee in $71 \%$ yield.

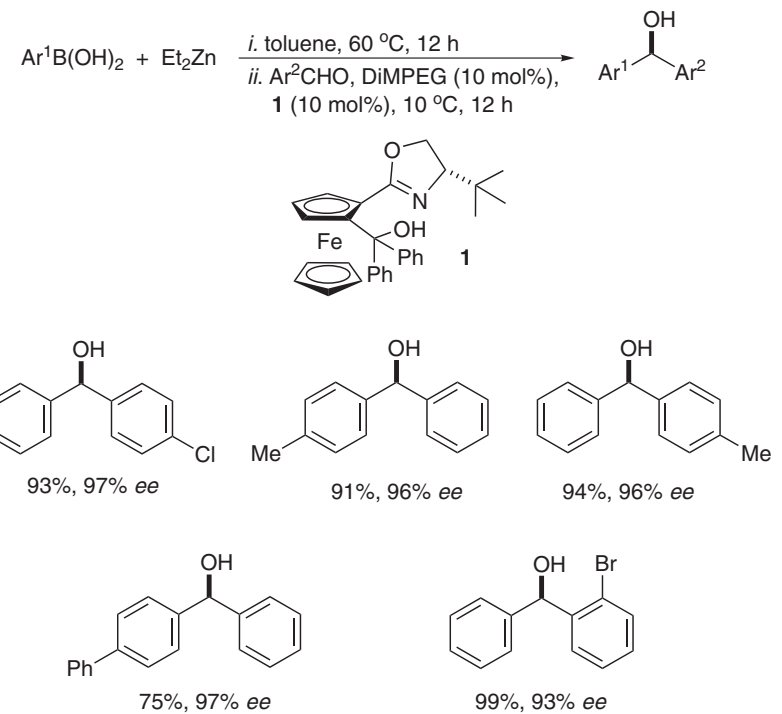

Scheme 7.

Another modification that has been developed in the field is the use of triphenylborane as the source of the transferable aryl group instead of the boronic acid and the same ferrocenyl oxazoline $\mathbf{1}$ was used as the chiral ligand. ${ }^{19}$ This protocol is also based on a boron-to-zinc exchange reaction by simply reacting $\mathrm{BPh}_{3}$ with a 3 -fold excess of diethylzinc in toluene to generate the reactive arylzinc species and similar levels of enantioselectivity were achieved in comparison with the boronic acid method (Scheme 8). Another chiral ligand that has been employed to mediate this enantioselective aryl addition is the silanol $\mathbf{2}$, which is an analogue of $\mathbf{1}$. This organosilanol showed a decreased performance since it catalyzed the arylation of 4-chlorobenzaldehyde in $73 \%$ yield and with a reduced $e e$ of $88 \%$ (Scheme 8$){ }^{20}$
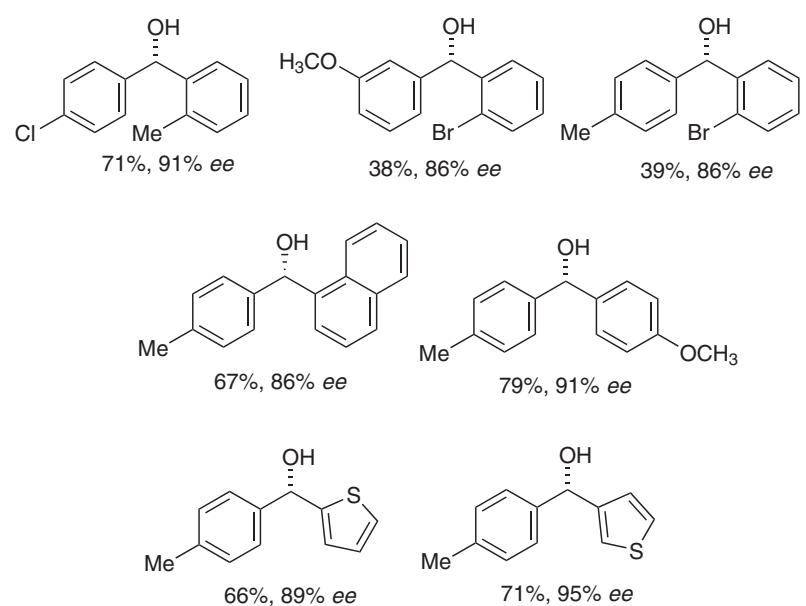

Figure 2. Products synthesized by aryl transfer to aromatic aldehydes. 


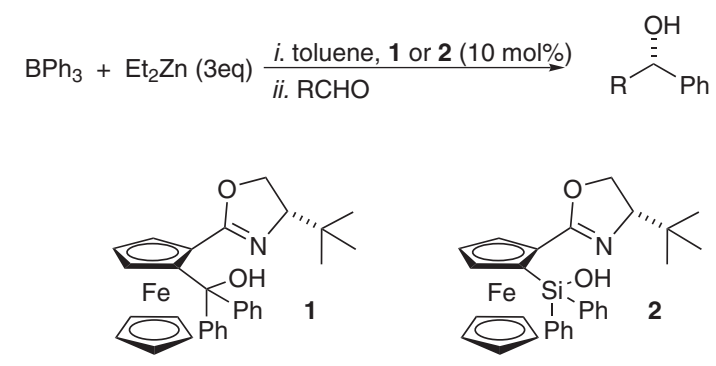<smiles>O[C@H](c1ccccc1)c1ccc(Cl)cc1</smiles>

with $198 \%, 97 \%$ ee

with $273 \%, 88 \%$ ee<smiles>Cc1ccc([C@@H](O)c2ccccc2)cc1</smiles>

$97 \%, 98 \%$ ee<smiles>OC(c1ccccc1)c1ccc(-c2ccccc2)cc1</smiles>

$88 \%, 98 \%$ ee

Scheme 8.

Recent studies by Wang and co-workers described enantioselective arylations of aryl aldehydes using arylboronic acids as aryl resource using chiral ferrocenyl alcohol as catalysts. The results showed that the $(2 S)-1$ ferrocenylmethylaziridin-2-yl(diphenyl)methanol 3 was a general catalyst for asymmetric addition of various ArZnEt, to the prochiral aldehydes with high enantioselectivities. ${ }^{21}$ In addition, the $R$ or $S$ enantiomers of a series of given diarylmethanols could be easily obtained in high yields with excellent enantioselectivities simply by the reverse combinations of both reaction partner.

In a further extension of this study, they demonstrated that the four-membered heterocycle-based $\mathbf{4}$ backbone has a good potential as chiral unit for the catalytic asymmetric induction reaction. The authors have also observed that the hindrance of the bulky ferrocenyl group played an important role in the enantioselective addition reactions (Scheme 9). ${ }^{22}$

Another catalytic system developed for the arylation of aldehydes with the $\mathrm{BPh}_{3} / \mathrm{Et}_{2} \mathrm{Zn}$ protocol were the oxazolinyl alcohols which are readily accessible from chiral sources such as amino alcohols (for the case of ligand $\mathbf{5})^{23}$ or mandelic acid (for the case of ligand 6). ${ }^{24}$ Arylation reaction in the presence of $10 \mathrm{~mol} \%$ of $\mathbf{6}$ afforded only low yields and $e e$ 's of the arylated product. However, ligand $\mathbf{5}$ has performed better and the diarylmethanols could be obtained with moderate enantioselectivity. The best result was obtained when 4-methoxybenzaldehyde was used and the corresponding product was isolated in $81 \%$ ee, albeit in only $60 \%$ yield (Scheme 10).

One of the easiest ways to increase the structural diversity of ligand libraries is to use amino acids chemistry,

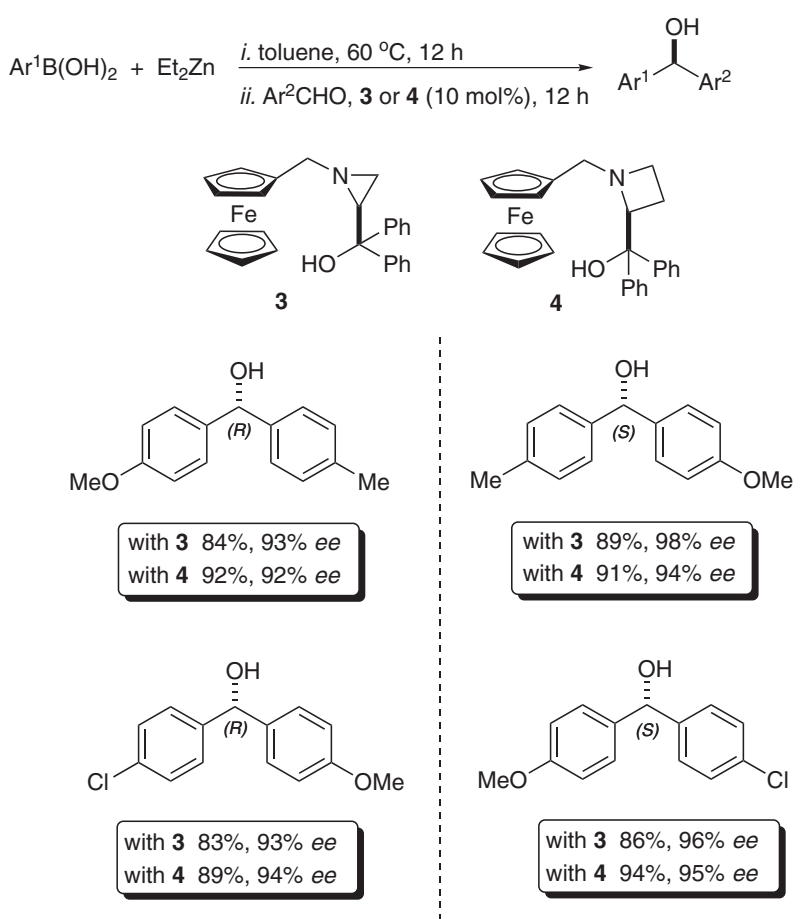

Scheme 9.

which is well established and highly modular. In 2005 Braga and co-workers ${ }^{25}$ reported on the use of $\beta$-amino alcohols 7 as chiral ligands in the enantioselective arylation of aldehydes using boronic acids as a suitable source of transferable aryl group. The desired products were obtained in high yields and excellent levels of enantiocontrol for a range of aldehydes and boronic acids (Scheme 11).

The best results were achieved using ligand $\mathbf{7 b}$ derived from $L$-valine $\left(\mathrm{R}=i\right.$-Pr) and $\mathrm{R}^{1}=\mathrm{Et}$ and the scope of the 


$$
\mathrm{BPh}_{3}+\mathrm{Et}_{2} \mathrm{Zn}(3 e q) \quad \frac{i . \text { toluene, } 5 \text { or } \mathbf{6}(10 \mathrm{~mol} \%)}{\text { ii. } \mathrm{RCHO} \text {, DiMPEG }(10-13 \mathrm{~mol} \%)}
$$<smiles>CC(C)(C)C1COC(C(O)C2=NC(C(C)(C)C)CO2)=N1</smiles><smiles>OC(c1ccccc1)c1ccc(Cl)cc1</smiles>

with $580 \%, 71 \%$ ee

with $620 \%, 35 \%$ ee<smiles>COc1ccc(C(O)c2ccccc2)cc1</smiles>

$60 \%, 81 \%$ ee<smiles>OC(c1ccccc1)c1ccccc1Br</smiles>

$85 \%, 55 \%$ ee

Scheme 10.

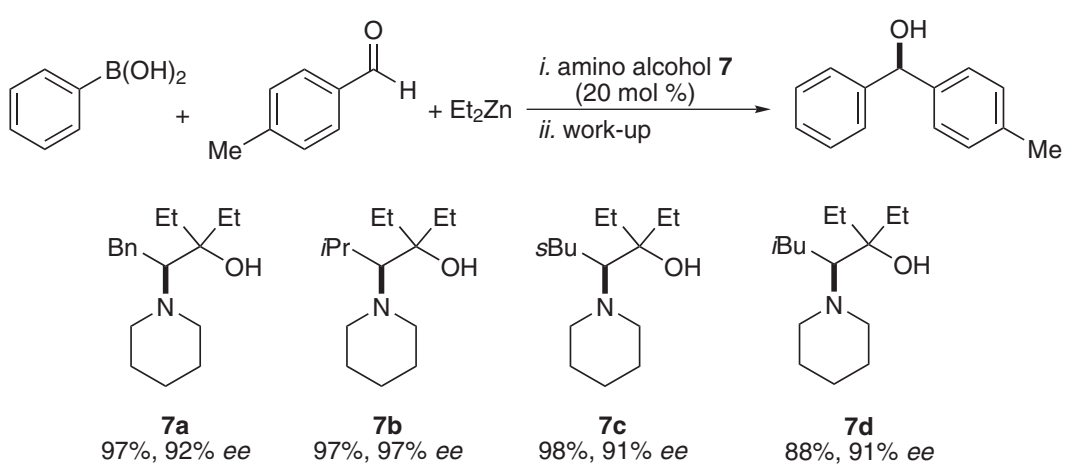

Yields and ee's refer to the arylation product

Scheme 11.

asymmetric aryl transfer was extended to several different aldehydes and boronic acids. Selected examples are shown in Scheme 12. The reactions with $o$ - and $p$-tolualdehyde underwent smooth aryl addition in very high enantiomeric excesses and with nearly quantitative yields. On the other hand, when an electron-withdrawing group such as chlorine, was present in the aldehyde, the enantioselectivity was also lower than when $p$-tolualdehyde was used. With regard to steric effects, it was observed that steric hindrance does play an important role in determining the degree of enantioselection. For instance, ortho- substituted benzaldehydes underwent aryl transfer with the same level of enantioselectivity as their para analogues. In order to examine if different aryl groups could be transferred to aldehyde with the same stereoselectivity, giving access to a range of substituted diaryl carbinols, the aryl transfer reactions of some substituted aryl boronic acids with benzaldehyde were studied and, excellent yields and $e e$ were obtained. Despite the small size of the library and the limited structural diversity, this work paved the way to all the subsequent developments.

In a subsequent work, Braga and coworkers reported application of pyrrolidinylmethanols $\mathbf{8}$ in the zinc-catalyzed enantioselective addition of boronic acids to aldehyde. ${ }^{26}$ Another successful application of pyrrolidinylmethanol ligands was the enantioselective aryl transfer reactions to aldehydes with boroxines as aryl source (Scheme 13). ${ }^{27}$

Recently, Dahmen described studies regarding the effect of additives in the phenyl transfer reactions to 2-bromobenzaldehyde using $N, N$-dibutylnorephedrine (DBNE) as chiral ligand and triphenylborane as aryl source. They found that the polyethylene glycol derivatives generally improve the enantioselectivity, presumably by complexing zinc salts and thereby reducing the importance of the background reaction. Alcohols, in contrast, react with the zinc reagent and influence the selectivity by formation 


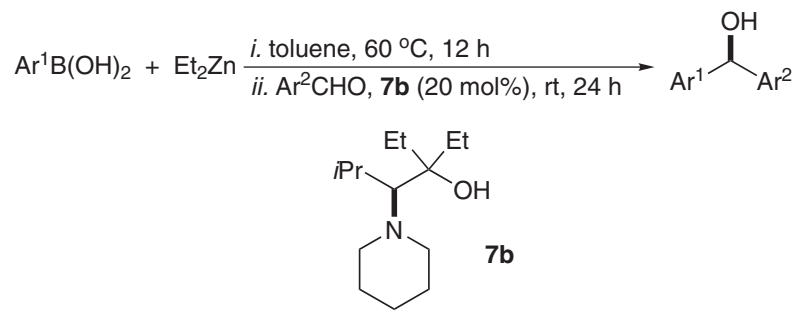<smiles>OC(c1ccccc1)c1ccc(Cl)cc1</smiles>

$87 \%, 89 \%$ ee<smiles>COc1ccc(C(O)c2ccccc2)cc1</smiles>

$98 \%, 94 \%$ ee<smiles>OC(c1ccccc1)c1ccc(Cl)cc1</smiles>

$97 \%, 94 \%$ ee<smiles>OC(c1ccccc1)c1ccccc1Br</smiles>

$91 \%, 89 \%$ ee<smiles>Cc1ccccc1C(O)c1ccccc1</smiles>

$93 \%, 97 \%$ ee<smiles>Cc1ccc(C(O)c2ccccc2)cc1</smiles>

97\%, $97 \%$ ee

Scheme 12.

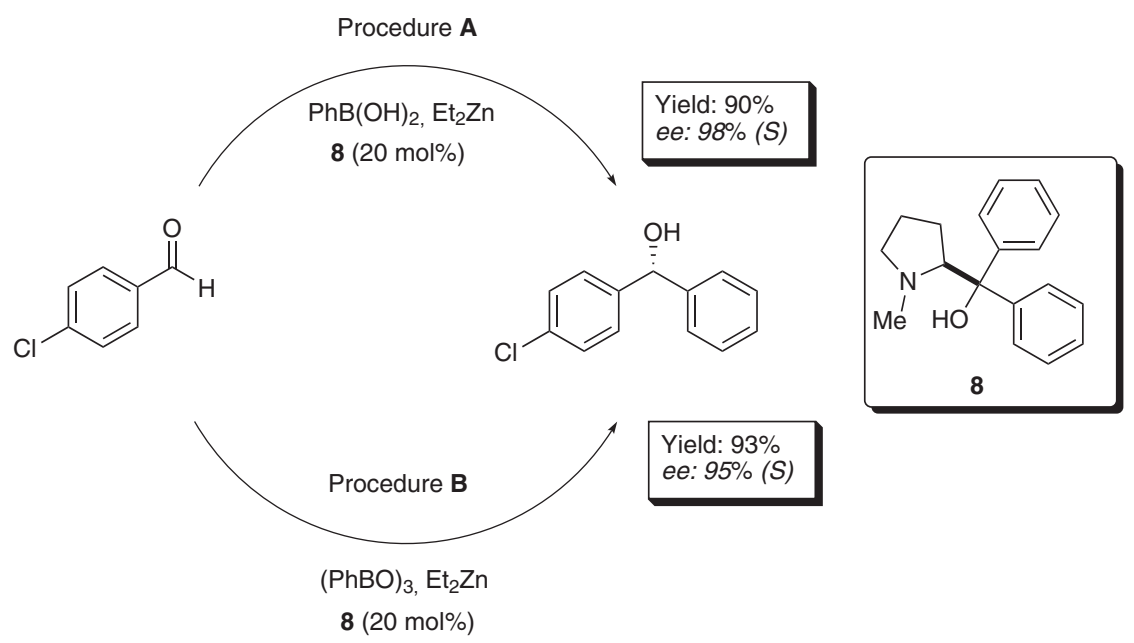

Scheme 13

of zinc alkoxides. The most interesting results observed by the authors were obtained with imidazole as additive, which led to a reversal in enantioselectivity. They could conclude that DiMPEG 2000 proved to be the best additive, giving an improvement of about $20 \%$ ee compared to the catalyzed reaction without additive (Scheme 14). ${ }^{28}$

In 2007, Braga and co-workers extended the application of this catalytic system with boronic acids serving as the aryl source. Application of various aldehydes in the phenyl transfer reaction using $N, N$-dibutylnorephedrine allowed the synthesis of diarylmethanols with up to $96 \%$ ee (Scheme 15). ${ }^{29}$

Another effective catalyst for enantioselective phenyl transfer reactions to aldehydes was reported by Zhong in $2007 .{ }^{30}$ They could easily prepare the cyclopropanebase chiral amino alcohols in three simple steps. Initially, the catalytic properties of this class of ligands were screened in the asymmetric phenyl transfer from a mixture of phenylboronic acids and diethylzinc to $p$-methylbenzaldehyde. The best result was obtained with $10 \mathrm{~mol} \%$ of ligand 9 in toluene at $-20^{\circ} \mathrm{C}$. Next, the phenyl transfer onto various aromatic aldehydes was investigated leading to products with good enantioselectivities (79-89\% $e e$ ), in excellent yields (83-90\%) (Scheme 16).

Recently, Braga and Wessjohann have demonstrated an efficient and very fast catalytic enantioselective arylation of aromatic aldehydes under microwave "flash-heating" using rigid chiral ligands. ${ }^{31}$ In preliminary experiments, the 


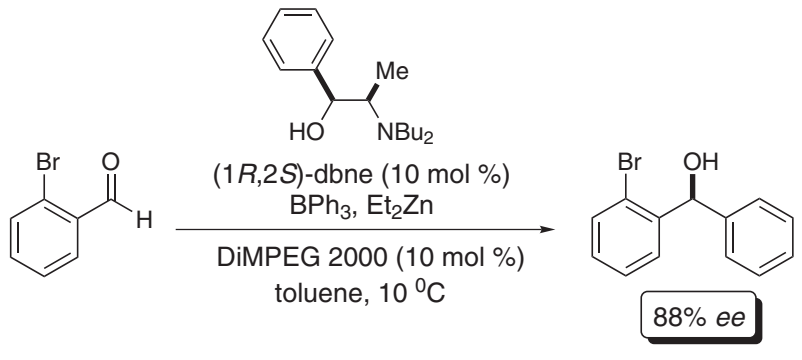

Scheme 14.

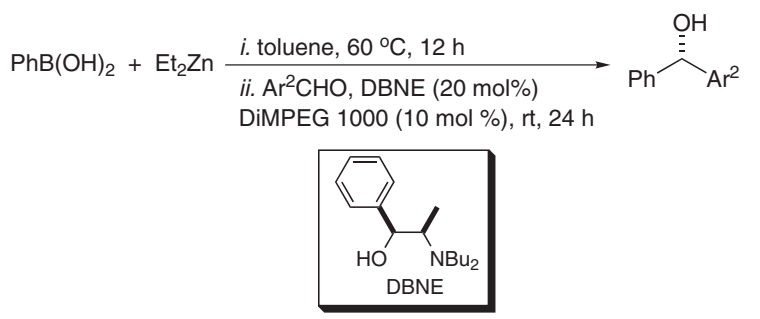

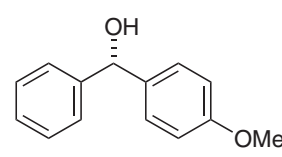

$87 \%, 86 \%$ ee

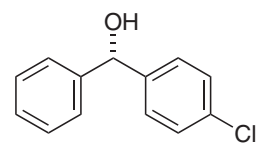

$98 \%, 90 \%$ ee

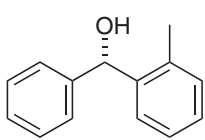

$92 \%, 96 \%$ ee

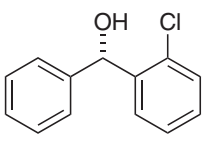

$98 \%, 80 \%$ ee
Scheme 15 . authors studied the reaction time required for the addition of the pre-formed arylzinc species to the aldehyde. In parallel with these studies, a new class of ligands for the asymmetric aryl transfer reaction was developed, namely aziridinemethanols. The best results were obtained using $10 \mathrm{~mol} \%$ of the catalyst 10 with $300 \mathrm{~W}$ of irradiation power and temperatures up to $60{ }^{\circ} \mathrm{C}$. Under these conditions, the product was obtained in only 5 min in $92 \%$ yield with $96 \%$ ee (Scheme 17).

More interestingly, though, is the fact that the reactive arylzinc species also could be effectively generated under microwave irradiation. Consequently, they found that the desired diarylmethanols could be obtained in high yields and $e e$ 's. Thus, the best reaction conditions established for this particular reaction consist of $10 \mathrm{~min}$ for the generation of the arylzinc species, followed by the addition of the catalyst and the appropriate aldehyde and an additional irradiation time of only 5 min with $300 \mathrm{~W}$ of irradiation power (Scheme 18). ${ }^{31}$ Other catalysts previously employed in the group were also tested, however, the best results were obtained with the aziridine-based amino alcohol 10 (97\% yield, $98 \% e e$ ). Important to mention is that for the first time, microwave energy has been used for the generation of reactive arylzinc species, starting from boronic acids. This new protocol improves significantly the catalytic performance of the system, leading to enantiomerically enriched diarylmethanols in very short reaction times, without compromising the enantioselectivity of the process.

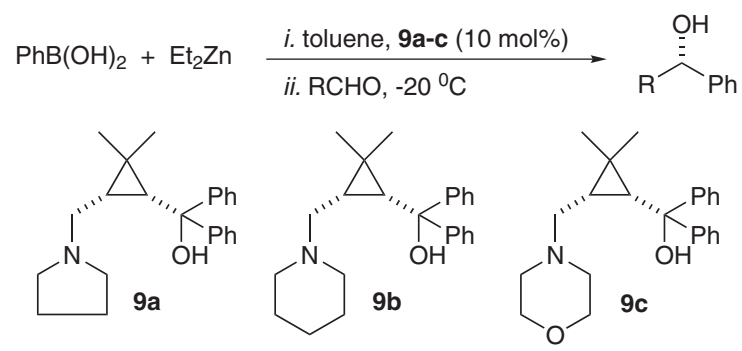

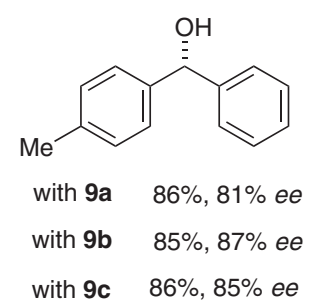

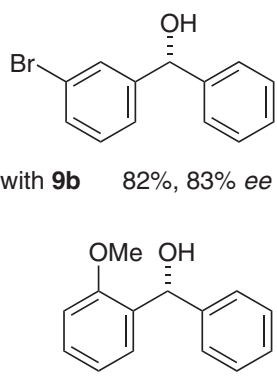

with $9 \mathrm{~b} \quad 88 \%, 89 \%$ ee

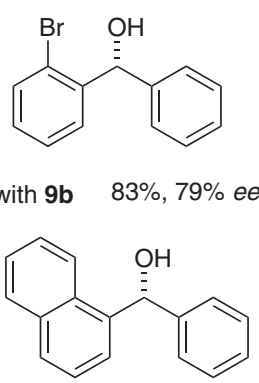

with 9 b $\quad 80 \%, 88 \%$ ee

Scheme 16. 


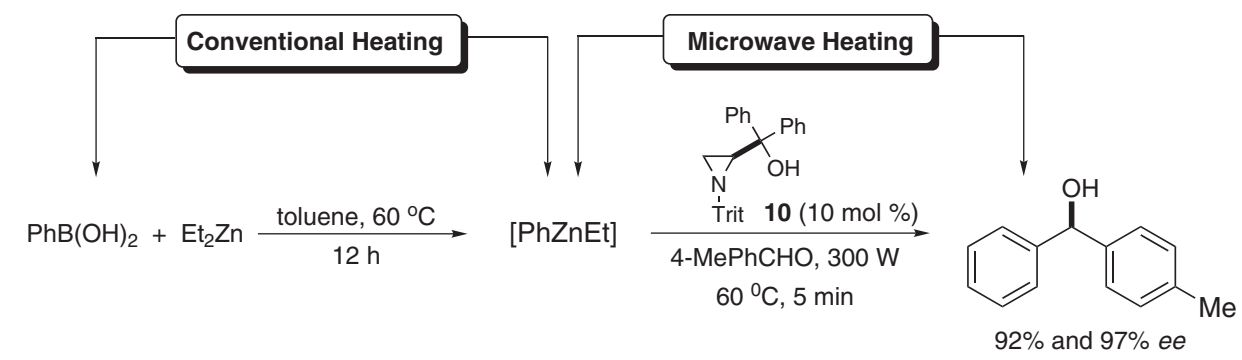

Scheme 17.

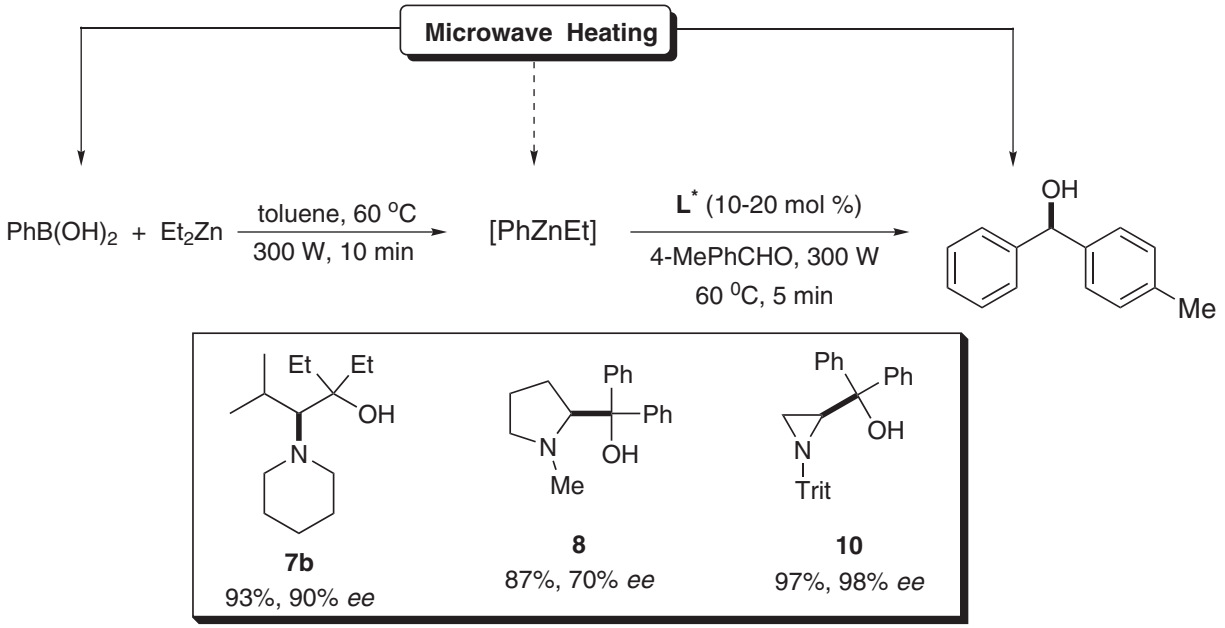

Yields and ee's refer to the arylation product

Scheme 18

The dendrimer-supported pyrrolidinylmethanol 11 was used by Zhao, Zhu and co-workers to mediate the reaction of arylzinc reagents with aldehydes (Figure 3). ${ }^{32,33}$ The enantioselectivity obtained with the use of the polymer was very close to that of the corresponding monomeric catalyst 8.

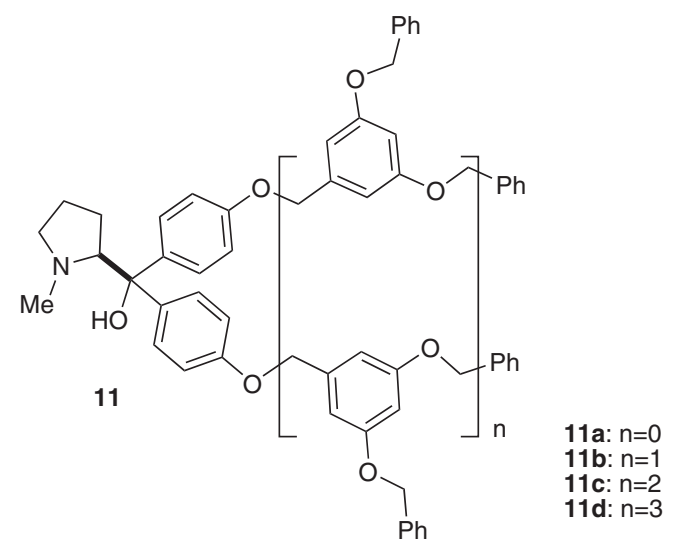

Figure 3 .
The best results were obtained using ligand 11c $(n=2)$, and the enantioselectivity of the arylation reaction was very high for a range of aromatic aldehydes (89-98\%). Moreover, one of the more relevant features of these dendritic ligands is the ease of their separation and reuse, due to their large molecular size and different solubility. Thus, by adding methanol to the reaction mixture, the quantitative precipitation of 11c occurred, which was recovered by filtration. The recovered ligand was reused at least five times with little or no loss of activity and enantioselectivity (Scheme 19).

\subsection{Asymmetric aryl transfer reaction with sulfur- containing ligands}

Sulfur-containing ligands have also been employed in the enantioselective arylation of aldehydes. For example, Uang and co-workers have developed a camphorderived ligand 12, with a $\gamma$-amino thiol moiety, which was successfully applied in the asymmetric arylation of several aromatic aldehydes. ${ }^{34}$ Once again, the source of 

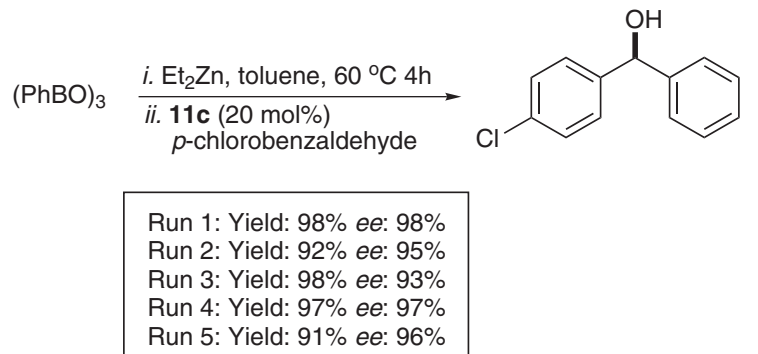

Scheme 19.

the transferable aryl group was the corresponding boronic acid. Initial studies employing phenylboronic acid and $p$-tolualdehyde revealed that the best results were achieved in the presence of $10 \mathrm{~mol} \%$ of $\gamma$-amino thiol 12 at -35 ${ }^{\circ} \mathrm{C}$, for a period of $48 \mathrm{~h}$. It is worth mentioning that the best results were observed when a mixture of toluene and hexanes (1:3) was used as the reaction solvent. This is particularly interesting, since the commercial solution of diethylzinc in hexanes in less expensive than the corresponding toluene solution. The optimal condition was extended to other arylboronic acids and aromatic aldehydes and high yields and excellent enantiomeric excesses were obtained (Scheme 20).

In this same context, Braga and co-workers also developed an efficient and modular synthesis of chiral thiazolidines, based on the readily available amino acids $(R)$ cysteine and $(R)$-penicyllamine. ${ }^{35}$ These chiral thiazolidines were evaluated as ligands for the asymmetric aryl transfer reaction with arylboronic acids and the chiral diarylmethanol product were obtained with moderate to good $e e$ 's. From these studies, it was observed that the size of the ester group plays an important role in the enantioselection event. With larger substituents at the ester function, higher $e e$ 's of the products were obtained. Further refinements on the structure were made and it was found that a gem-dibutyl group in the thiazolidine ring resulted in improved $e e$ 's of the diarylmethanol products. Moreover, ligands derived from $(R)$-cysteine displayed better catalytic behavior than the similar compound derived from $(R)$-penicyllamine. For example, the direct comparison between compounds $\mathbf{1 3 b}$ and $13 \mathbf{c}$ as ligands in the catalytic aryl transfer reaction reveals that $\mathbf{1 3 b}$, which is derived from $(R)$-cysteine delivers the desired product in higher yields and ee's (97\% yield, $81 \%$ ee vs. $79 \%$ yield, $52 \%$ ee; see Scheme 21). This indicates that the steric bulkiness around the sulfur atom decreases the ability of the ligand to coordinate to zinc, thus disfavoring the enantioselective pathway.

Very recently, an interesting study comparing the catalytic performance of amino alcohols with their thioacetate analogues was described. ${ }^{36}$ The authors observed that the thioacetate ligands were remarkably superior to the corresponding amino alcohols. For example, the phenylation of 4-chlorobenzaldehyde could be accomplished in the presence of $2.5 \mathrm{~mol} \%$ of the chiral thioacetate 15, and the corresponding diarylmethanol was isolated in high yields and excellent enantioselectivity. On the other hand, when the amino alcohol 14 with the

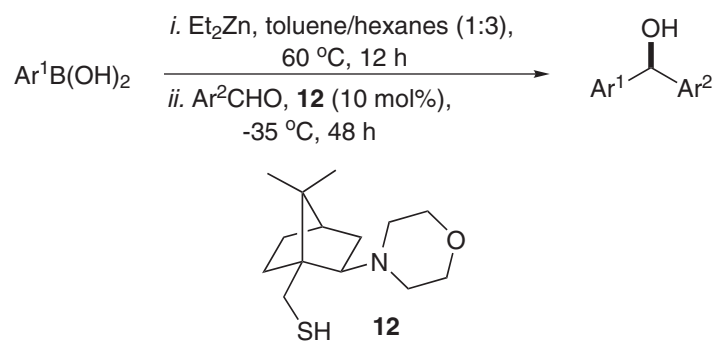

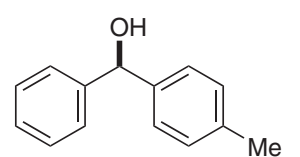

$87 \%, 97 \%$ ee<smiles>Cc1ccccc1C(O)c1ccccc1</smiles>

$90 \%,>99.5 \%$ ee<smiles>OC(c1ccccc1)c1ccc(C(F)(F)F)cc1</smiles>

$83 \%, 97 \%$ ee<smiles>OC(c1ccccc1)c1ccc2ccccc2c1</smiles>

$73 \%, 95 \%$ ee<smiles>CC(=O)c1ccc(C(O)c2ccccc2)cc1</smiles>

$84 \%, 96 \%$ ee

Scheme 20. 


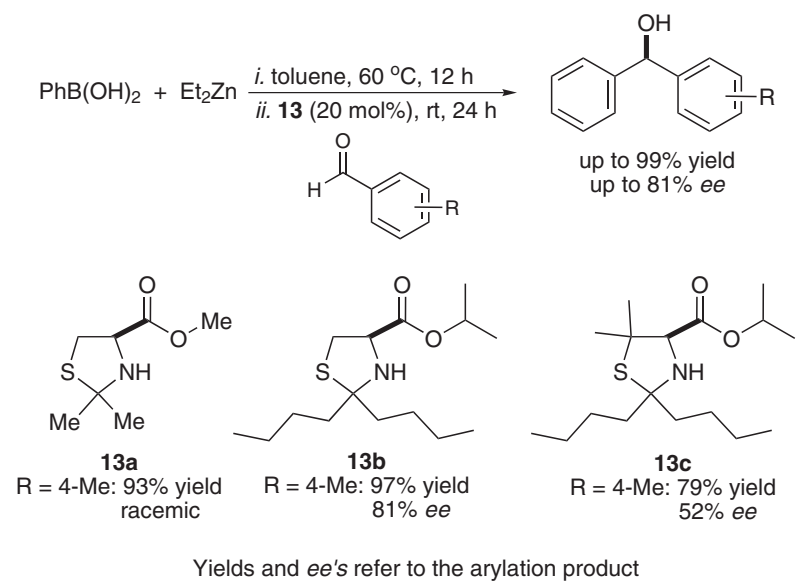

Scheme 21.

same framework was tested, ${ }^{29}$ the product was achieved in very low ee (Scheme 22). The authors explain this higher efficiency due to a stronger affinity of sulfur toward zinc or arylzinc species.

Another remarkable feature of this catalytic system is that the chiral thioacetates can be used in very low amounts, being effective even when $1 \mathrm{~mol} \%$ of ligand is used.

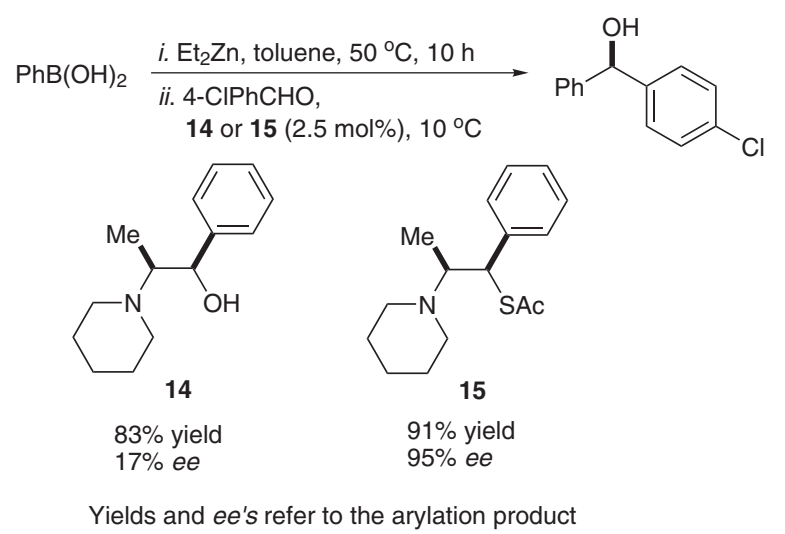

Scheme 22.

The catalytic system was extended to several different combinations of aromatic aldehydes and arylboronic acid, possessing both electron donating and electron withdrawing groups. High yields and $e e$ 's were achieved in the presence of $2.5 \mathrm{~mol} \%$ of the thioacetate $\mathbf{1 5}$ and some selected examples are shown in Figure 4.

The combination of triarylboroxines as the aryl source and chiral sulfur ligands has also produced some interesting results. Zhao and co-workers develop a class of thiopheneoxazoline ligands, prepared from the condensation of a thiophene derivative with chiral amino alcohols. ${ }^{37}$ These compounds were applied in the phenylation of several aromatic aldehydes with moderate enantioselectivities

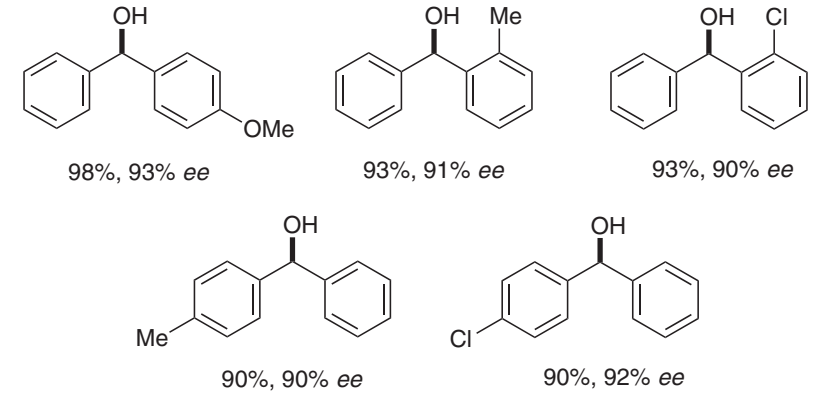

Figure 4. Selected examples prepared using $2.5 \mathrm{~mol} \%$ of thioacetate $\mathbf{1 5}$

(Scheme 23). The best ligand was found to have the oxazoline moiety derived from S-Me- $(R)$-cysteine (ligand 16), promoting the reaction between triphenylboroxine and $p$-chlorobenzaldehyde in $91 \%$ yields and $82 \% e e$. The scope of the phenyl transfer was examined to other aldehydes and $e e$ 's in the range of $60-82 \%$ were obtained.

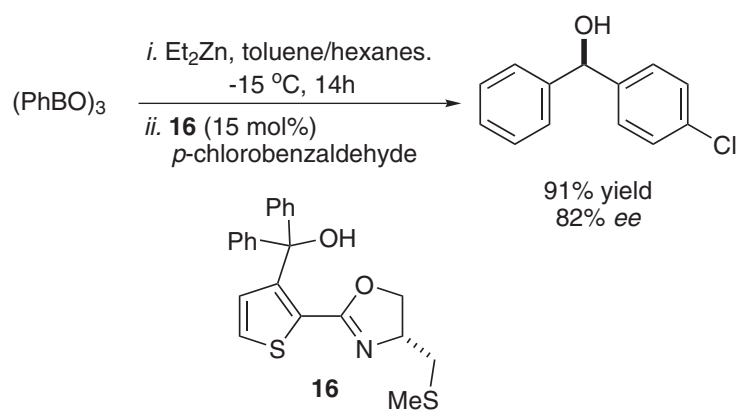

Scheme 23.

\subsection{Asymmetric aryl transfer reaction with binol-type ligands}

Some excellent binaphthol ligands have also been studied. Ito and Katsuki developed a binaphthol-derived ligand 17, which has shown excellent reactivities and enantioselectivities in asymmetric addition of boronic acids to aldehydes (Scheme 24). ${ }^{38}$ For example, the reaction of $p$-chlorobenzaldehyde with ethylphenylzinc at $0{ }^{\circ} \mathrm{C}$ in toluene/TBME in the presence of $10 \mathrm{~mol} \% \mathbf{1 7}$ produced (S)-4-chlorophenyl-phenylmethanol with $95 \%$ ee.

Chan and co-workers applied the chiral tertiary aminonaphthol ligand 18a in asymmetric arylation-type reactions. ${ }^{39}$ The reaction is conducted under the same conditions as mentioned above with Bolm's catalyst $\mathbf{1}$ (Scheme 7), although the best enantioselectivity was obtained at $-15^{\circ} \mathrm{C}$, in high yields and enantioselectivities. A similar chiral aminonaphtol ligand $\mathbf{1 8 b}$ was used by Dahmen and co-workers, to perform the arylation of aldehydes. The authors employed several different aryl 
<smiles>CCCCNC(=O)c1cc2ccccc2c(-c2c(O)c(C(=O)NCCCC)cc3ccccc23)c1O</smiles>

17

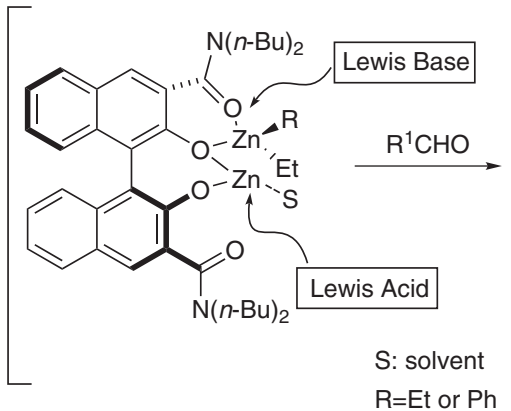

$\mathrm{R}=\mathrm{Et}$ or $\mathrm{Ph}$

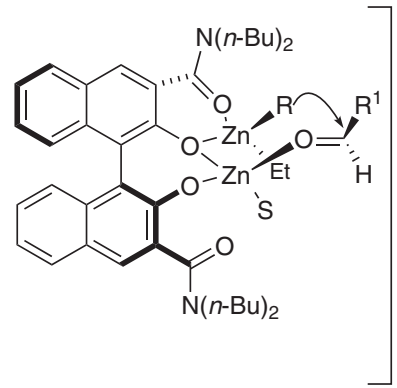

${ }_{R^{1}}^{\mathrm{OH}_{R}^{H}}$

Scheme 24.

sources and have found that triarylborane ammonia complexes are the ideal precursors of the arylzinc reagent for their catalytic system (Scheme 25). ${ }^{40}$

In the same way, Chan also described the synthesis of a series of atropisomeric binaphthyl-derived amino alcohols and their application in the catalytic asymmetric phenyl transfer reaction to aromatic and aliphatic aldehydes. ${ }^{41}$ The salient features of these chiral amino alcohol ligands include their ease of preparation and the flexibility of modifications on both the binaphthyl moiety and the amino alcohol backbone. The best result was obtained with ligand 19, which gave the chiral alcohol with $96 \%$ ee. The match of the configurations between the binaphthyl blackbone and the phenyl substituent alpha to the amino moiety was quite important for obtaining high enantioselectivity in the product. In contrast, the mismatched configuration of 20 was detrimental to the enantioselectivity (69\% ee). Amino alcohol ligands containing phenyl substituents
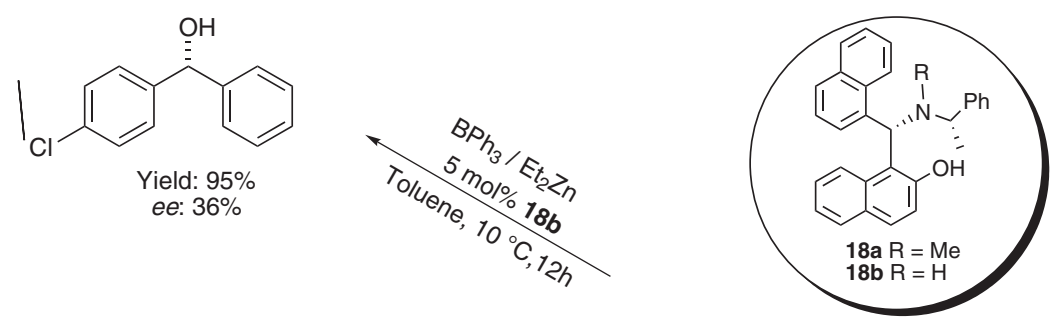<smiles>O[C@H](c1ccccc1)c1ccc(Cl)cc1</smiles>

$\mathrm{H}_{3} \mathrm{~N} \rightarrow \mathrm{B}(\mathrm{Ph})_{3} / \mathrm{Et}_{2} \mathrm{Zn}$

\section{$5 \mathrm{~mol} \% 18 \mathrm{~b}$}<smiles>O[C@H](c1ccccc1)c1ccc(Cl)cc1</smiles>

Toluene, $10^{\circ} \mathrm{C}, 12 \mathrm{~h}$

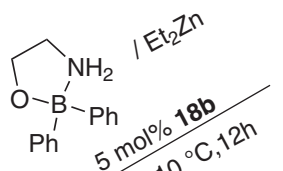<smiles>O=Cc1ccc(Cl)cc1</smiles>

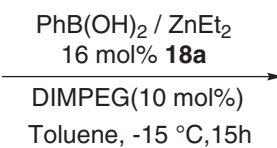<smiles>OC(c1ccccc1)c1ccc(Cl)cc1</smiles>
ee: $94 \%$

\section{Scheme 25.}



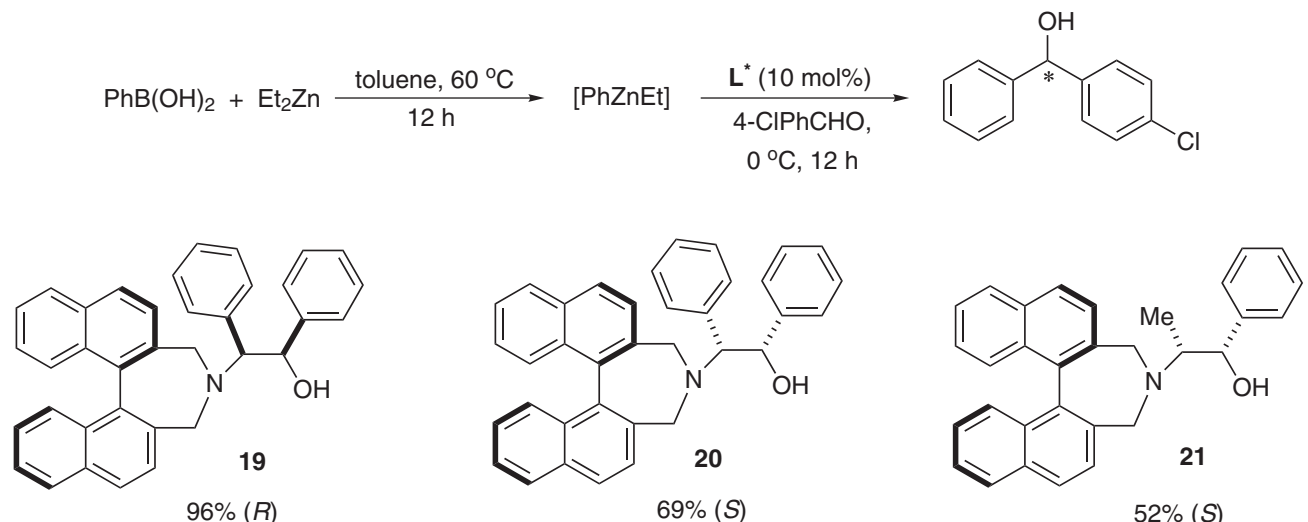

BINOL-derived chiral ligands

Yields and ee's refer to the arylation product

Scheme 26.

at the 2-position were found to be more effective than those containing a methyl substituent. In most cases, the configuration of the alcohol product could be correlated with the chirality of the amino alcohol moiety of the ligand (Scheme 26).

Under the newly developed catalytic system, the authors could observe that the scope of substrates was not limited to para-substituted aromatic aldehydes, the meta- or even ortho-substituted substrates also afforded the corresponding products with good yields and excellent $e e$ 's. They found, that not only the yields of the addition products, but also the enantioselectivities were uniformly high (>97\% ee). Aromatic aldehydes possessing steric hindrance, such as 1-naphthaldehyde and 2-naphthaldehyde, also proved to be suitable substrates for the asymmetric phenylation reaction. The in situ prepared phenylzinc reagent also worked well for the phenyl addition to other aldehydes, particularly aliphatic aldehydes, furaldehyde, and $\alpha, \beta$-unsaturated trans-cinnamyl aldehydes, giving products with good to excellent ee's in most cases (Table 1).

\subsection{Asymmetric aryl transfer reaction with sulfonamide ligands}

In 2003, Yus discovered that the arylzinc reagent, prepared in situ by the boron-to-zinc exchange of phenylboronic acid with a solution of diethylzinc, could also add to ketones to generate chiral tertiary alcohols in the presence of camphorsulfonamide derivatives $\mathbf{2 2}$ (Scheme 27). ${ }^{42}$ The aforementioned result was slightly worse than using pure diphenylzinc. After $24 \mathrm{~h}$, the chemical yield was only $79 \%$, various by-products being detected resulting from ethyl addition and ketone auto-aldol condensation processes. The lower enantioselection, as well as the chemical yield, might be attributed to the presence of organoboronate salts and therefore to side-reactions promoted by them.

Recently, the same authors studied the catalytic arylation of ketones using trans-1-arenesulfonyl-amino2-isoborneolsulfonylaminocyclohexane $\mathbf{2 3}$ as ligand. The corresponding phenylzinc intermediate was obtained starting from commercially available triphenylboron by transmetallation with diethylzinc by heating in toluene at $70{ }^{\circ} \mathrm{C}$. This intermediate was reacted in situ with parabromoacetophenone in the presence os substoichiometric amounts of ligands 23a-b and a small excess of titanium tetraisopropoxide giving the expected diarylethanol derivative with excellent enantioselectivities (Scheme 28). ${ }^{43}$ Although the actual catalysts for these bis(sulfonamide) ligand systems are still not determined, analogy can be made to the mechanistic aspects described for the enantioselective addition of diethylzinc to aldehydes. ${ }^{44}$ These bis(sulfonamide) ligands most likely bind to titanium in a multidentate fashion to generate the active catalyst, which then adopts a $C_{2}$-symmetric disposition in the transition state. Furthermore, in this bimetallic system, the role of the dioorganozinc reagent is more likely to transfer the organic group to titanium, which then delivers it to the aldehyde.

\section{Application in Large Scale Synthesis}

A very interesting application of the methodology presented herein consists in large scale synthesis of the 
Table 1. Asymmetric aryl transfer reaction, employing binaphtol ligand 19

$$
\mathrm{PhB}(\mathrm{OH})_{2}+\mathrm{Et}_{2} \mathrm{Zn} \frac{i \cdot \text { toluene, } 60^{\circ} \mathrm{C}, 12 \mathrm{~h}}{i i \cdot \mathrm{RCHO}, 19(10 \mathrm{~mol} \%)}
$$

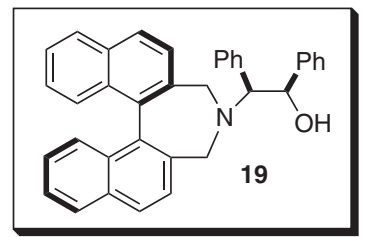

\begin{tabular}{|c|c|c|c|c|c|}
\hline Entry & $\mathrm{RCHO}$ & Product & $\mathrm{T} /\left({ }^{\circ} \mathrm{C}\right)$ & Yield $/(\%)$ & ee /(\%) \\
\hline 1 & & & 0 & 96 & $96(\mathrm{R})$ \\
\hline 2 & & & 0 & 95 & $94(\mathrm{R})$ \\
\hline 3 & & & -20 & 96 & $90(\mathrm{R})$ \\
\hline 4 & & & -20 & 95 & 99(R) \\
\hline 5 & & & -20 & 94 & 93(R) \\
\hline 6 & & & 0 & 91 & $95(\mathrm{R})$ \\
\hline 7 & & & -20 & 91 & 92(R) \\
\hline 8 & & & -20 & 96 & 79(R) \\
\hline 9 & & & 0 & 96 & 91(R) \\
\hline 10 & & & 0 & 88 & $96(\mathrm{R})$ \\
\hline
\end{tabular}

metabotropic glutamate receptor (mGlu2) potentiators. The mGlu2 are a class of G-protein-coupled receptors, being largely presynaptic and generally inhibiting neurotransmission. ${ }^{45}$ Thus, compound $\mathbf{2 9}$ is a key intermediate in the industrial synthesis of potential therapies for the acute treatment of migraine headaches and it is needed in multikilogram scale. The method of choice to prepare the chiral diarylmethanol was the asymmetric arylation of 3-cyano benzaldehyde, using arylboronic acid $\mathbf{2 4}$ or triarylboroxine $\mathbf{2 5}$ as the source of a transferable aryl group. ${ }^{46}$
Initially the boron-to-zinc exchange reaction was performed with diethylzinc, resulting in the corresponding arylzinc reagent. Addition of the chiral amino alcohol ligand (15 mol\%) and DiMPEG (11 mol\%), followed by injection of the aldehyde 27 , resulted in a smooth reaction and the corresponding diarylmethanol $\mathbf{2 8}$ was isolated in $95 \%$ yield and $>94 \% e e$. This product was successfully converted to the target compound $\mathbf{2 9}$ in a few synthetic steps. Important to mention is that the reaction was run in pilot plant using $17.6 \mathrm{~kg}$ of the aldehyde 27 with results 


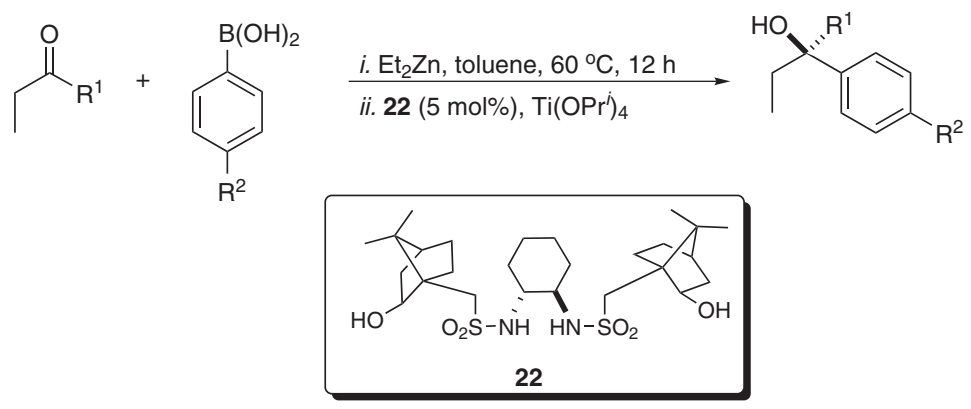

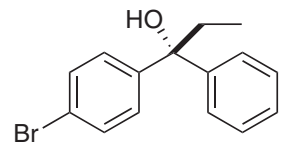

$79 \%, 81 \%$ ee<smiles>CC[C@@](O)(c1ccccc1)c1ccc(C)cc1</smiles>

$58 \%, 84 \%$ ee

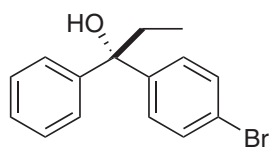

$65 \%, 93 \%$ ee

Scheme 27.

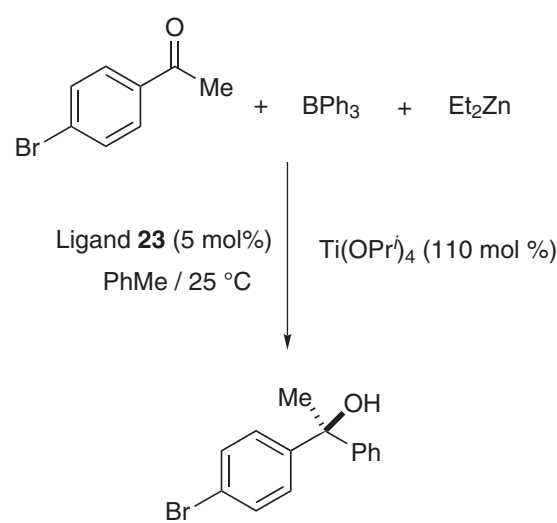

with ligand 23a: $120 \mathrm{~h} 90 \%$, ee $>99 \%$ with ligand 23b: 24 h $96 \%$, ee $>99 \%$

Scheme 28 .

comparable to those obtained in the laboratory scale (Scheme 29).

\section{Summary and Outlook}

In the past 20 years there has been dramatic growth in the use of transition metal catalysis in synthetically important organic transformations. Recently, increased attention has been paid to zinc catalysts in the catalytic, enantioselective arylation of aldehydes. In this context, an interesting protocol was recently introduced, which takes advantage of the use of boron compounds as the source of the nucleophilic aryl species, by a boron-zinc exchange reaction with diethylzinc. Although much progress has been made in developing this chemistry, many challenges and questions still remain. A deeper understanding of the mechanism and the factors that govern the formation of the presumably transferable arylzinc species from different organometallic reagents will allow for innovation in ligand design and reduce the amounts of ligand necessary to achieve high enantioselectivities. Certainly, in the near future, many advances are forthcoming that will turn this methodology into a robust and efficient way to access valuable, enantiopure building blocks with broad applications to the synthesis of biologically important molecules.

In addition, the arylation of other carbonyl compounds and derivatives, such as poorly electrophilic ketones and 


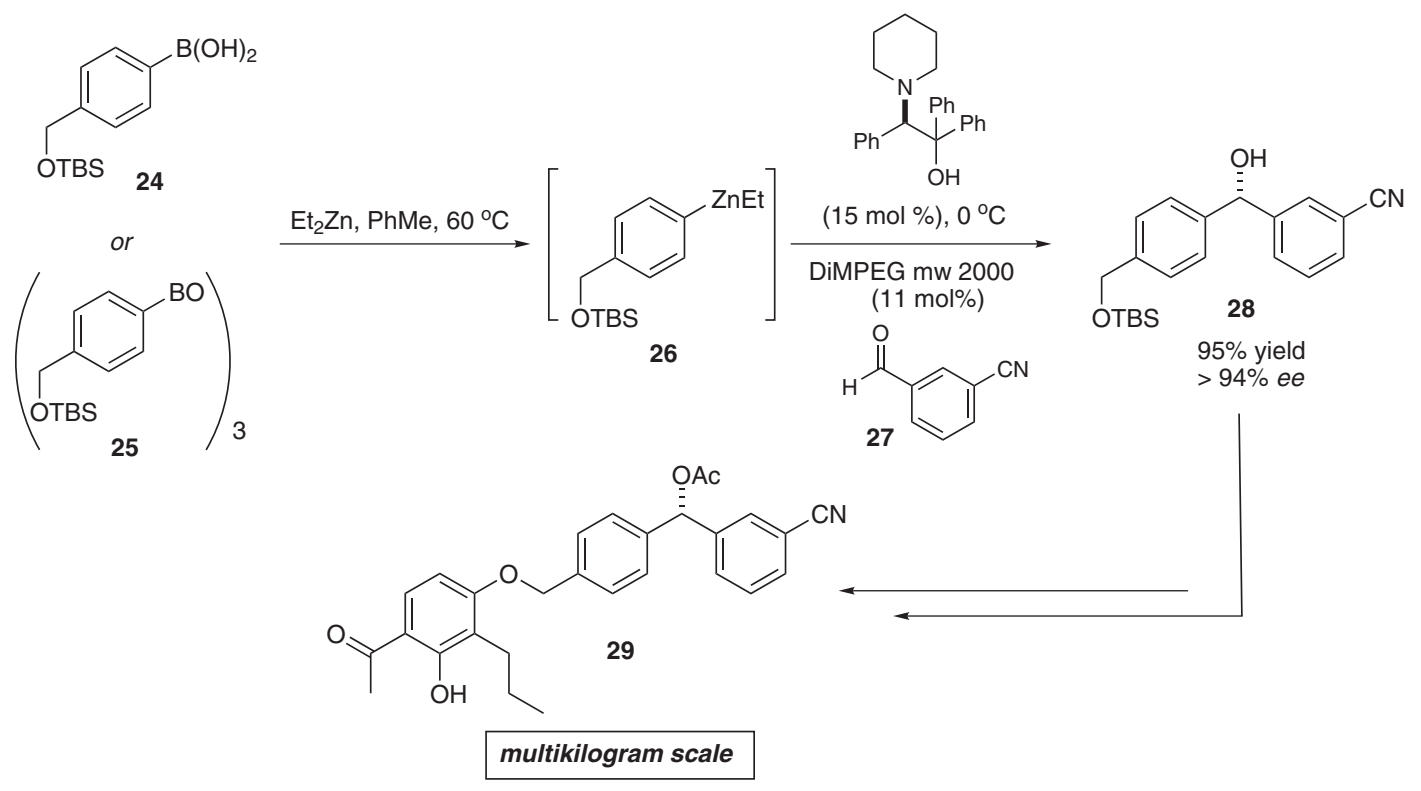

Scheme 29.

imines would be a welcome advance. This area is developing at a rapid pace and surely further progress in both ligand design and mechanistic insight will be forthcoming.

\section{Acknowlegments}

We are pleased to acknowledge our collaborators, whose names appear in the references, for their dedication and devotion to the development of our own work presented herein. The authors are indebted to CAPES, CNPq and FAPESP for financial support.

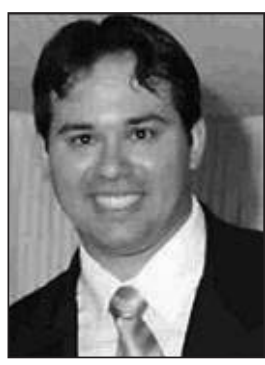

Márcio Weber Paixão was born in Cachoeira do Sul, RS, Brazil, in 1979. He received his B.S. in Chemistry in 2003 from the Universidade Federal de Santa Maria (South Brazil). In 2007, he completed his Ph.D. at the same university under the supervision of Prof. Antonio L. Braga, working with catalytic enantioselective synthesis. During his Ph.D. studies, he worked as a visiting scientist (six months) with Prof. Ludger A. Wessjohann in Halle, Germany. He immediately started the postdoctoral fellow in the laboratory of Prof. João V. Comasseto at the Universidade de São Paulo (Brazil). Following this, he joined the Center for Catalysis (University of Aarhus-DK), where he currently working with Professor Karl Anker Jørgensen. His research interests are focused on the design, preparation, and application of new chiral ligands in asymmetric catalysis as well as in asymmetric organocatalysis.

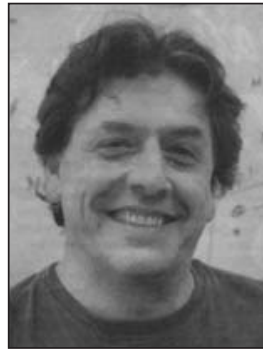

Antonio Luiz Braga was born in Tupã (SP State) and obtained his $B S c$ in 1982 from the Universidade Federal de São Carlos (SP State). He received his $M S c$ and $P h D$ degrees from the Universidade de São Paulo in 1984 and 1989, working under the direction of Prof. J. V. Comasseto in the field of Organic Selenium Chemistry. In 1985 he obtained a position at the Universidade Federal de Santa Maria-RS (south Brazil) as Assistant Professor and currently is still at the same place as Professor of Organic Chemistry. He is also a 1A-level researcher of CNPq (Brazilian National Research Council). His research interests mainly reside in the catalytic cpplications of chiral crganochalcogen compounds in asymmetric synthesis as well as in the preparation of organoselenium compounds with relevant biological activities.

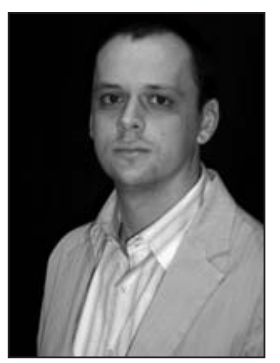

Diogo Seibert Lüdtke was born in Cachoeira do Sul, RS, Brazil in 1979. He received his B.S. in Chemistry in 2000 from the Universidade Federal de Santa Maria. In 2001, he entered the graduate program at the same University, where in 2005 he completed his Ph.D., under the supervision of Prof. Antonio L. Braga, working with the synthesis of chiral selenium-containing amino acid derivatives and peptides as well as with catalytic enantioselective synthesis mediated by chiral selenium 
ligands. After a postdoctoral stint in the group of Prof. Ronaldo A. Pilli, at the Universidade Estadual de Campinas, he started his independent career in 2007, as assistant professor at the Universidade de São Paulo. His primary research interests are focused in the design and preparation of new chiral ligands and catalysts from readily available sources, such as amino acids and carbohydrates, and their application in asymmetric catalysis. Furthermore, he is also interested in the synthesis of chiral organochalcogen compounds with potential biological activities.

\section{References}

1. For comprehensive reviews of organozinc additions to carbonyl compounds, see: Noyori, R.; Kitamura, M. Angew. Chem., Int. Ed. Engl. 1991, 30, 49; Soai, K.; Niwa, S. Chem. Rev. 1992, 92, 833; Noyori, R. In Asymmetric Catalysis in Organic Synthesis; Wiley: New York, 1994; ch 5; Pu, L.; Yu, H. -B. Chem. Rev. 2001, 101, 757; Pu, L. Tetrahedron 2003, 59, 9873.

2. Meguro, K.; Aizawa, M.; Sohda, T.; Kawamatsu, Y.; Nagaoka, A. Chem. Pharm. Bull. 1985, 33, 3787; Toda, F.; Tanaka, K.; Koshiro, K. Tetrahedron: Asymmetry 1991, 2, 873; Stanchev, S.; Rakovska, R.; Berova, N.; Snatzke, G. Tetrahedron: Asymmetry 1995, 6, 183; Botta, M.; Summa, V.; Corelli, F.; Di Pietro, G.; Lombardi, P. Tetrahedron: Asymmetry 1996, 7, 1263.

3. For a reviews on catalyzed asymmetric arylation reactions, see: Bolm, C.; Hildebrand, J. P.; Muñiz, K.; Hermanns, N. Angew. Chem. Int. Ed. 2001, 40, 3284; Schmidt, F.; Stemmler, R. T.; Rudolph, J.; Bolm, C. Chem. Soc. Rev. 2006, 35, 454; Dimitrov, V.; Kostova, K. Lett. Org. Chem. 2006, 3, 176.

4. Spencer, C. M.; Foulds, D.; Peters, D. H. Drugs 1993, 46, 1055; Devalia, J. L.; De Vos, C.; Hanotte, F.; Baltes, E. Allergy 2001, $56,50$.

5. Bolshan, Y.; Chen, C. -Y.; Chilenski, J. R.; Gosselin, F.; Mathre, D. J.; O’Shea, P. D.; Roy, A.; Tillyer, R. D. Org. Lett. 2004, 6, 111; O'Shea, P. D.; Chen, C. -Y.; Chen, W. R.; Dagneou, P.; Frey, L. F.; Grabowski, E. J. J.; Marcantonio, K. M.; Reamer, R. A.; Tan, L.; Tillyer, R. D.; Roy, A.; Wang, X.; Zhao, D. L. J. Org. Chem. 2005, 70, 3021.

6. Harbinson, P. L.; MacLeod, D.; Hawksworth, R.; O’Toole, S.; Sullivan, P. J.; Heath, P.; Kilfeather, S.; Page, C. P.; Costello, J.; Holgate, S. T.; Lee, T. H. Eur. Respir. J. 1997, 10, 1008; Torphy, T. J.; Barnette, M. S.; Underwood, D. C.; Griswold, D. E.; Christensen,S. B.; Murdoch, R. D.; Nieman, R. B.; Compton, C. H. Pulm. Phamacol.Ther. 1999, 12, 131; Burnouf, C.; Pruniaux, M.-P. Curr. Pharm. Des. 2002, 8, 1255; Timmer, W.; Leclerc, V.; Birraux, G.; Neuhauser,M.; Hatzelmann, A.; Bethke, T.; Wurst, W. J. Clin. Pharmacol. 2002,42, 297.

7. Dosa, P. I.; Ruble, J. C.; Fu, G. C. J. Org. Chem. 1997, 62, 444.
8. Huang, W. -S.; Hu, Q. -S.; Pu, L. J. Org. Chem. 1999, 62, 7940.; Bolm, C.; Muñiz, K. Chem. Comm. 1999, 1295; Ko, D. -H.; Kim, K. H.; Há, D. -C. Org. Lett. 2002, 4, 3759.

9. Bolm, C.; Hermanns, N.; Hildebrand, J. P.; Muñiz, K. Angew. Chem. Int. Ed. 2000, 39, 3465; Bolm, C.; Kesselgruber, M.; Hermanns, N.; Hildebrand, J. P. Angew. Chem. Int. Ed. 2001, 40, 1488.

10. Fontes, M.; Verdaguer, X.; Solà, L.; Pericàs, M. A.; Riera, A. J. Org. Chem. 2004, 69, 2532.

11. For B-to-Zn exchange reactions see: Srebnik, M. Tetrahedron Lett. 1991, 32, 2449; Oppolzer, W.; Radinov, R. N. Helv. Chim. Acta 1992, 75, 170; Oppolzer, W.; Radinov, R. N. J. Am. Chem. Soc. 1993, 115, 1593; Langer, F.; Schwink, L.; Devasagayaraj, A.; Chavant, P. -Y.; Knochel, P. J. Org. Chem. 1996, 61, 8229; Boudier, A.; Bromm, L. O.; Lotz, M.; Knochel, P. Angew. Chem. Int. Ed. 2000, 39, 4414.

12. Bolm, C.; Rudolph, J. J. Am. Chem. Soc. 2002, 124, 14850.

13. Rudolph, J.; Bolm, C.; Norrby, P. -O. J. Am. Chem. Soc. 2005, 127, 1548; Rudolph, J.; Rasmussen, T.; Bolm, C.; Norrby, P. -O. Angew. Chem. Int. Ed. 2003, 40, 3002.

14. Jimeno, C.; Sayalero, S.; Fjermestad, T.; Colet, G.; Maseras, F.; Pericàs, M, A. Angew. Chem. Int. Ed. 2008, 47, 1098.

15. Yamakawa, M.; Noyori, R. J. Am. Chem. Soc. 1995, 117, 6327; Kitamura, M.; Suga, S.; Oka, H.; Noyori, R. J. Am. Chem. Soc. 1998, 120, 9800; Goldfuss, B.; Houk, K. N. J. Org. Chem. 1998, 63, 8998; Itsuno, S.; Fréchet, J. M. J. J. Org. Chem. 1987, 52, 4142 .

16. For the DiMPEG effect, see: Rudolph, J.; Hermanns, N.; Bolm, C. J. Org. Chem. 2004, 69, 3997.

17. Rudoph, J.; Schmidt, F.; Bolm, C. Synthesis 2005, 840.

18. Schmidt, F.; Rudolph, J.; Bolm, C. Adv. Synth. Catal. 2007, 349, 703.

19. Rudolph, J.; Schmidt, F.; Bolm, C. Adv. Synth. Catal. 2004, $346,867$.

20. Ozcubukcu, S.; Schmidt, F.; Bolm, C. Org. Lett. 2005, 7, 1407.

21. Wang, M. -C.; Wang, X. -D.; Ding, X.; Liu, Z. -K. Tetrahedron 2008, 64, 2559.

22. Wang, M-C.; Zhao, W-X.; Wang, X-D.; Song, M-P. Synlett 2006, 3443; Wang M. -C.; Zang, Q. -J.; Zhao, W. -X.; Wang, X. -D.; Ding X.; Jing T. -T.; Song M. -P. J. Org. Chem. 2008, $73,168$.

23. Bolm, C.; Schmidt, F.; Zani, L. Tetrahedron: Asymmetry 2005, 16, 1367.

24. Bolm, C.; Zani, L.; Rudolph, J.; Schiffers, I. Synthesis 2004, 2173.

25. Braga, A. L.; Lüdtke, D. S.; Vargas, F.; Paixao, M. W. Chem. Commun. 2005, 2512.

26. Braga, A. L.; Lüdtke, D. S.; Schneider, P. H.; Vargas, F.; Schneider, A.; Wessjohann, L. A.; Paixao, M. W. Tetrahedron Lett. 2005, 46, 7827. 
27. Wu, X.; Liu, X., Zhao, G. Tetrahedron: Asymmetry 2005, 16, 2299

28. Rudolph, J.; Lormann, M.; Bolm, C.; Dahmen, S. Adv. Synth. Catal. 2005, 347, 1361.

29. Paixão, M. W.; De Godoi, M.; Rhoden, C. R. B.; Westermann, B.; Wessjohann, L. A.; Lüdtke, D. S.; Braga, A. L. J. Mol. Cat. A: Chem. 2007, 261, 120.

30. Zhong, J.; Guo, H.; Wang, M.; Yin, M.; Wang, M. Tetrahedron:Asymmetry 2007, 18, 734.

31. Braga, A. L.; Paixão, M. W.; Westermann, B.; Schneider, P. H.; Wessjohann, L. A. J. Org. Chem. 2008, 73, 2879.

32. Liu, X. Y.; Wu, X. Y., Chai, Z.; Wu, Y. Y.; Zhao, G.; Zhu, S. Z. J. Org. Chem. 2005, 70, 7432.

33. Polymer-supported ferrocenyl oxazoline 1 was also previously employed in the arylation of aldehydes using the $\mathrm{Ph} 2 \mathrm{Zn} / \mathrm{Et} 2 \mathrm{Zn}$ system. Bolm, C.; Hermanns, N.; Claßen, A.; Muniz, K. Bioorg. Med. Chem. Lett. 2002, 12, 1795.

34. Wu, P. -Y.; Wu, H. -L.; Uang, B. - J. J. Org. Chem. 2006, 71, 833.

35. Braga, A. L.; Milani, P.; Vargas, F.; Paixão, M. W.; Sehnem, J. A. Tetrahedron: Asymmetry 2006, 17, 2793.

36. Jin, M. -J.; Sarkar, S. M.; Lee, D. -H.; Qiu, H. Org. Lett. 2008, 10,1235 .

37. Chai, Z.; Liu, X. -Y.; Wu, X. -Y.; Zhao, G. Tetrahedron: Asymmetry 2006, 17, 2442.
38. Ito, K.; Tomita, Y.; Katsuki, T. Tetrahedron Lett. 2005, 46, 6083.

39. Ji, J. -X.; Wu, J.; Au-Yeung, T. T. -L.; Yip, C. -W.; Haynes, R. K.; Chan, A. S. C. J. Org. Chem. 2005, 70, 1093.

40. Dahmen, S.; Lormann, M. Org. Lett. 2005, 21, 4597.

41. Lu, G.; Kwong, F. Y.; Ruan, J. -W.; Li, Y. -M.; Chan, A. S. C. Chem. Eur. J. 2006, 12, 4115.

42. Prietro, O., Ramón, D. J.; Yus, M. Tetrahedron: Asymmetry 2003, 14, 1955.

43. Forrat, V. J.; Ramón, D. J., Yus, M. Tetrahedron:Asymmetry 2005, 20, 3341 .

44. Walsh, P. J. Acc. Chem. Res. 2003, 36, 739; Betancort, J. M.; García, C.; Walsh, P. J. Synlett 2004, 749.

45. Lam, A. G. M.; Soriano, M. A.; Monn, J. A.; Schoepp, D. D.; Lodge, D.; McCulloch, J. Neurosci. Lett. 1998, 254, 121; Kingston, A. E.; O’Neill, M. J.; Lam, A.; Bales, K. R.; Monn, J. A.; Schoepp, D. D. Eur. J. Pharmacol. 1999, 377, 155; Helton, D. R.; Tizzano, J. P.; Monn, J. A.; Schoepp, D. D.; Kallman, M. J. J. Pharmacol. Exp. Ther. 1998, 284, 651.

46. Magnus, N. A.; Anzeveno, P. B.; Coffey, D. S.; Hay, D. A.; Laurila, M. E.; Schkeryantz, J. M.; Shaw, B. W.; Staszak, M. A. Org. Proc. Res. Dev. 2007, 11, 560.

Received: March 4, 2008 Web Release Date: June 2, 2008

FAPESP helped in meeting the publication costs of this article. 